\title{
Enhancement of TiB Grain Refining Effect on A356 Gravity Die Casting with the Addition of Yttrium
}

\section{Lim Ying Pio, Wang Chan Chin}

Department of Mechanical Engineering, Universiti Tunku Abdul Rahman, Kuala Lumpur, Malaysia.

Email: yingpio_lim@yahoo.com

Received July $9^{\text {th }}, 2012$; revised August $12^{\text {th }}, 2012$; accepted September $14^{\text {th }}, 2012$

\begin{abstract}
The present work investigates the effect yttrium on the grain refining efficiency of Al-5Ti-1B in gravity die cast A356 aluminum alloy. A series of casting experiments were carried out in which the Ti and B contents were maintained constantly at 0.1 and $0.02 \mathrm{wt} \%$ respectively. The inoculation level of yttrium was manipulated at the amount of $0,0.1,0.2$, 0.3, 0.4 and $0.5 \mathrm{wt} \%$. Microstructural characterization of the as-cast A356 alloy was investigated by means of optical microscope and its phases are detected by XRD. XRF is used to determine the contents of inoculating elements such as $\mathrm{Ti}, \mathrm{B}$ and $\mathrm{Y}$ so that their actual optimal ratio in the casting can be approximated. The mechanical properties tested are tensile strength and hardness. The inoculation of yttrium was found to enhance the grain refinement effect of Al-5Ti-1B grain refiner and improve the mechanical properties. The optimal weight percentage of yttrium was discovered to be 0.3 . The grain refining efficiency of combining yttrium and Al-5Ti-1B on A356 aluminum alloy was mainly attributed to the heterogeneous nucleation of $\mathrm{TiB}_{2}$ and $\mathrm{TiAl}_{3}$ particles which were dispersed more evenly in the presence of yttrium and also as a result of $\alpha-\mathrm{Al}$ grain growth restriction by $\mathrm{AlY}_{3}$ compound precipitated at grain boundaries during solidification.
\end{abstract}

Keywords: Al-5Ti-1B Grain Refiner; Gravity Dies Casting; Mechanical Testing; Microstructure; XRD; XRF; Yttrium

\section{Introduction}

In the past decades, a great deal of work had been done on improving the mechanical properties and castability of aluminum alloys in foundry industries through modification and grain refinement techniques. Modification of as-cast Al-Si alloys (eutectic or hypoeutectic) has been a well-known practice employed for refining the large size eutectic silicon needles to fine fibrous or lamellar in its final solidified morphology [1]. The morphology of eutectic Si can be changed by modifier additives from its original coarse acicular structure to a finer fibrous structure resulting in significant enhancement of the mechanical properties of Al-Si castings like improved tensile strength and fatigue strength [2]. It has been concluded in a number of experimental work of researchers that modification of eutectic silicon can be achieved by several methods like faster solidification, mold vibration, melt agitation in mushy zone by electromagnetic force and melt inoculation by using some elements like $\mathrm{Na}, \mathrm{Sr}$, $\mathrm{Sb}$ etc. Typical modifier such as $\mathrm{Sr}$ has efficient modification effect but its efficiency drops with longer melt holding time. On the other hand, Sb demonstrates good modification on longer melt treatment time [3]. Besides modification, grain refinement of $\mathrm{Al}-\mathrm{Si}$ alloys with the addition of grain refiners into the melt before pouring is also a major melt treatment encountered in foundries. The advantages of grain refinement of aluminum alloys are both technical and economic, which include reduced ingot cracking, better ingot homogeneity [4], being less susceptible to hot cracking [5] and mechanical properties are improved significantly too [6]. Grain refinement improves the quality of castings by reducing the size of primary $\alpha$-Al grains nucleated in the as-cast product, which otherwise will solidify naturally with coarse columnar grain structure in the absence of grain refiner. Fine equiaxed grain structure is desired because it comes along with several benefits such as uniform distribution of second phases and microporosity to improve homogeneity, improved feeding ability to avoid incomplete filling of mold [7], reduced porosity and the elimination of hot tearing, high yield strength, high toughness, improved machinability and excellent deep drawability of the products [8].

Aluminium alloys are the major lightweight metals used in various industries for applications ranging from automotive components to aerospace parts etc. [9]. It is a continuous improvement program in casting industries to improve the microstructure of casting in terms of reduc- 
ing grain size and modification of eutectic phase so that its inherent mechanical properties of aluminum alloys castings can be enhanced. This direction is becoming more important due to the increasing awareness of reducing greenhouse emissions by using lightweight materials in the automotive industries. Aluminium alloys have excellent strength to weight ratio compared with other conventional metals like steels and A356 is one of the most widely used aluminum alloys in many industrial applications because of its excellent castability, corrosion resistance and good mechanical properties. It has lower production cost, fast machining rate and good recyclability. Typical commercial grain refiners use to refine A356 aluminum castings are Al-Ti-B and Al-Ti-C master alloys. The efficiency of these grain refiners can be easily undermined by the presence of elements like $\mathrm{Zr}$ and $\mathrm{V}$ [10]. In recent years, yttrium has arisen as a promising element in superalloys for its ability to improve creep property and oxidation resistance of cast stainless steel [11,12]. A previous study by Song M., Chen K. H. et al. [13] indicates that rare earth element like yttrium can improve the strength of Al-Zn-M-Cu alloy at elevated temperature. However, there is not much work has been done to investigate the effect of yttrium on the grain refining efficiency of Ti-B based grain refiner in A356 casting. Therefore, the current investigation attempts to study the effect of yttrium on the grain refinement efficiency of Al-Ti-B master alloy by using gravity die casting as the casting process.

\section{Materials and Methods}

In this study, the commercial A356 aluminum alloy was used as the base metal in all castings. The liquidus and the solidus temperatures of the alloy were found to be $615^{\circ} \mathrm{C}$ and $538.5^{\circ} \mathrm{C}$ respectively according to manufacturer's data. The grain refiners used are Al-5Ti-1B master alloy supplied by KBM AFFILIPS. The rare earth used is Yttrium of 99.9\% purity. The manufacturer's data of the compositions of the A356 alloy, Al-5Ti-1B master alloy are given in Table $\mathbf{1}$.

The gravity die casting mold used is designed according to JIS H5202 standard which contains two cavities of cylindrical shape tensile test piece of gage length $50 \mathrm{~mm}$

Table 1. Compositions of A356, Al-5Ti-1B and Tical315.

\begin{tabular}{ccccccc}
\hline wt\% & Si & Fe & Mn & B & C & Ti \\
\hline A356 & 7.22 & 0.15 & 0.01 & - & - & 0.13 \\
Al-5Ti-1B & 0.1 & 0.16 & - & 1.0 & - & 5.0 \\
wt\% & Ni & Zn & Sr & Mg & Al & \\
A356 & 0.016 & 0.04 & 0.01 & 0.45 & Bal & \\
Al-5Ti-1B & - & - & - & - & \multicolumn{2}{c}{ Bal } \\
\hline
\end{tabular}

and diameter $14 \mathrm{~mm}$. The internal configuration of the mold is shown in Figure 1.

The surface of the mold was coated with a layer of mold release agent in order to facilitate casting knockout after pouring and solidification. The A356 aluminum alloy was put into the crucible of a Nabertherm electrical furnace and melted up to $750^{\circ} \mathrm{C} \pm 5^{\circ} \mathrm{C}$. After complete melting, calculated fixed quantity of Al-5Ti-1B which constitutes the weight percentages of $0.1 \mathrm{Ti}$ and $0.02 \mathrm{~B}$ were added into the melt and stirred for 30 seconds before the addition of yttrium. The quantity of yttrium was added as $0.1,0.2,0.3,0.4$ and $0.5 \mathrm{wt} \%$ in separate experiment. The molten alloy was then directly poured into the gravity die casting mold.

The castings are purposely designed for ultimate tensile strength test. They were subjected to fettling and cleaning and subsequently machined to a diameter of 20 $\mathrm{mm}$ at the gripping ends. The as-cast samples and machined samples are shown in Figure 2. The tensile test was done on INSTRON 5582 with a tensile rate of 2 $\mathrm{mm} / \mathrm{min}$. The central part of the tensile specimen was cut

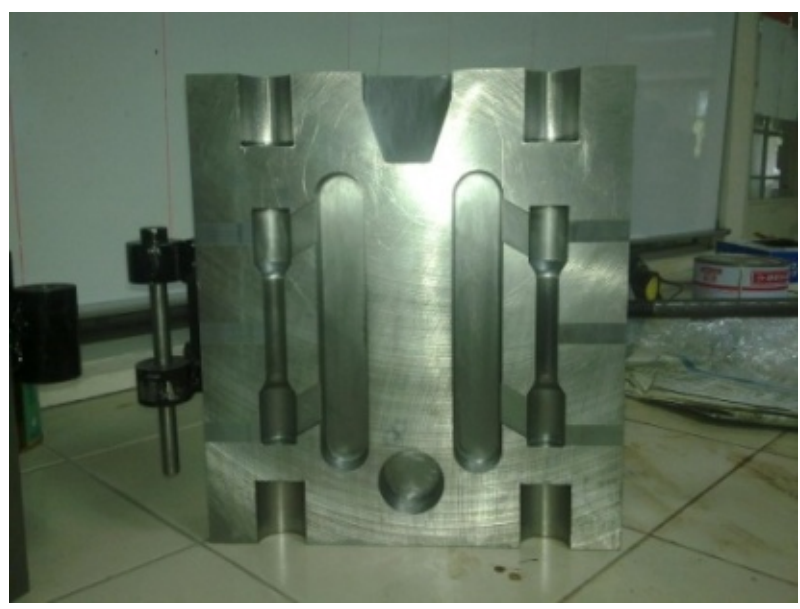

Figure 1. Gravity die casting mold.

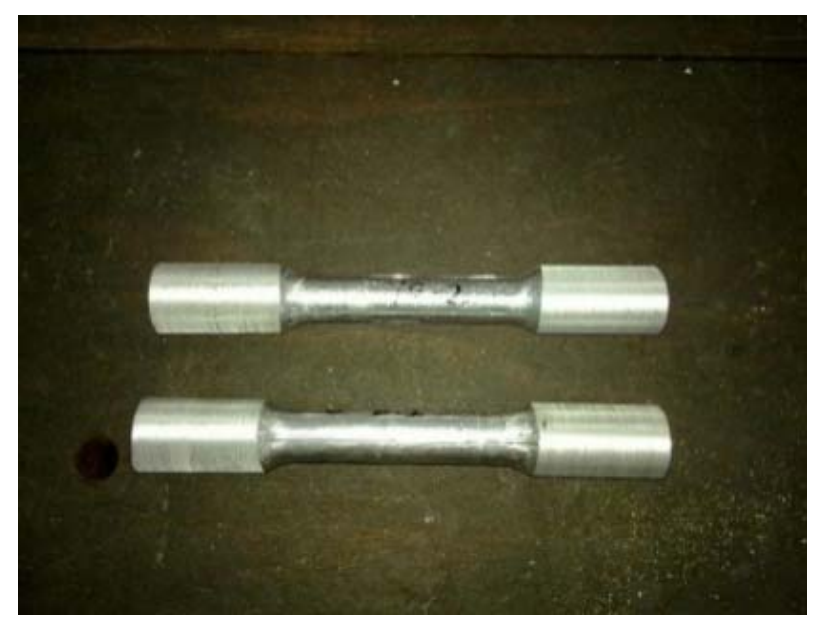

Figure 2. Gravity die casting samples. 
to a thickness of $10 \mathrm{~mm}$ and subjected to fine 80 grit-size grinding on both sides to smoothen the coarse surfaces for hardness test. The hardness test was done on Indentec Universal Hardness Tester. The scales of all tests were set to be HRA $60 \mathrm{kgf}$.

A sample of size $5 \mathrm{~mm} \times 5 \mathrm{~mm}$ was cut from the transverse plane at the central part of each tensile specimen and mounted in resin to prepare for grinding, rough polishing and finally fine polishing to the fineness of 0.3 micron. The polishing agent was buehler alpha alumina particles of 0.3 micron. The samples were chemically treated with etchant consisting of $200 \mathrm{ml}$ distilled water and $5 \mathrm{ml} \mathrm{HF}$. Microstructural studies were conducted by using an optical microscope with a maximum magnification power of $2000 \times$. Similarly polished samples of 0.3 $\mathrm{mm}$ thickness were used for XRD examination. Before every examination experiment by $\mathrm{XRD}$, the XRD machine was calibrated to ensure its detection was correct.

\section{Results and Discussions}

The main results obtained from this study are the mechanical properties of ultimate tensile strength, hardness and elongation (strain at fracture). The original A356 data is used as benchmark to deter-mine the performance of yttrium on Al-5Ti-1B grain refinement in A356 gravity dies casting. The microstructures taken by optical microscope will be compared to analyze the effect of yttrium on grain size. XRD analysis results is used to find out is there any special phase formed in the casting after adding yttrium as inoculants.

\subsection{Hardness}

The hardness of original A356 is 19.84. The $0.1 \mathrm{wt} \% \mathrm{Ti}$ and $0.02 \mathrm{wt} \% \mathrm{~B}$ increases the hardness to 21.62. Keeping the contents of $\mathrm{Ti}$ and $\mathrm{B}$ constant, the addition of yttrium from 0.1 to $0.3 \mathrm{wt} \%$ also shows improvement in hardness with the values of $21.10,22.16$ and 23.88 respectively. However, continuous addition of 0.4 and $0.5 \mathrm{wt} \%$ does not further improve hardness but reduces it to 18.02 and 17.08 respectively. The results show that the best hardness value is obtained by inoculating $0.3 \mathrm{wt} \%$ of yttrium in combination with $0.1 \mathrm{wt} \% \mathrm{Ti}$ and $0.02 \mathrm{wt} \% \mathrm{~B}$ into the A356 casting. The graph in Figure 3 shows the data of hardness vs. yttrium wt\%. 0 wt\% refers to the A356 casting without any grain refiners. This applies to other graphs in the following sections.

\subsection{Tensile Strength}

Two tensile test samples for each type of alloy were subjected to test and the averaged values are taken to plot the ultimate tensile strength chart as shown in Figure 4. It can be seen that $0.1 \mathrm{wt} \%$ yttrium does not improve the tensile strength too much; it has a tensile strength of

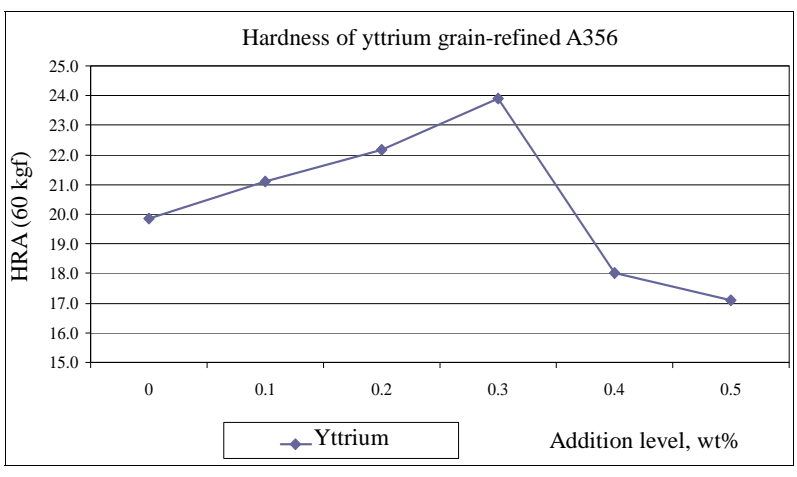

Figure 3. Hardness.

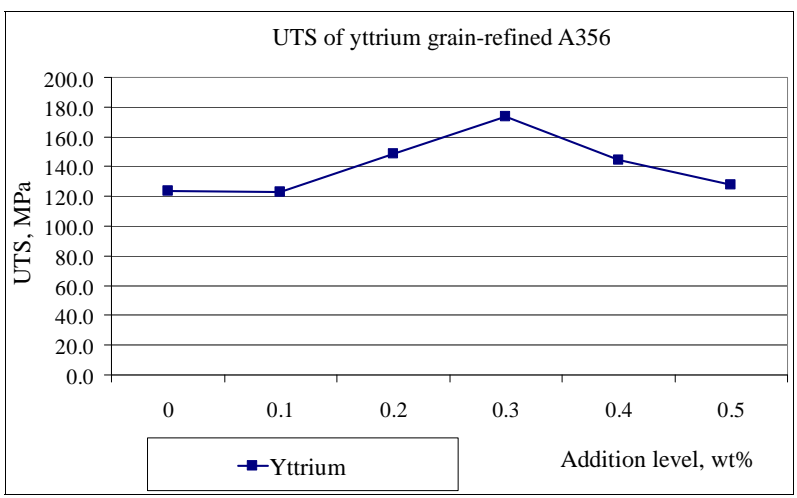

Figure 4. Ultimate tensile strength.

122.65 MPa while the original A356 has 123.49 MPa of tensile strength. The tensile strength increases when 0.2 and $0.3 \mathrm{wt} \%$ of yttrium is added, it improves to 148.29 and $173.40 \mathrm{MPa}$ respectively. However, further addition of yttrium does not improve tensile strength, instead, the tensile strength drops to 144.52 and $127.92 \mathrm{MPa}$ for 0.4 and $0.5 \mathrm{wt} \%$ of yttrium. The A356 containing $0.1 \mathrm{wt} \% \mathrm{Ti}$ and $0.02 \mathrm{wt} \% \mathrm{~B}$ has a tensile strength of $153.18 \mathrm{MPa}$, it is higher than the original A356 without grain refinement but lower than that added with $0.3 \mathrm{wt} \%$ yttrium. This indicates that yttrium is effective to improve the tensile strength of A356 casting by a maximum of $40 \%$. Based on the microstructures shown in Section 3.4, the addition of yttrium results in finer dendritic structure and more fibrous eutectic phase, this contributes to strengthening effect on the casting. Coarse and elongated silicon particles in eutectic phase of the unmodified A356 tends to fracture at lower tensile force while the refined and more fibrous silicon particles in yttrium-modified A356 are more resistant to dislocation under tension. The specimen which is solely grain-refined by Al-5Ti-1B also develops a better tensile strength as a result of finer dendritic structure due to the heterogeneous nucleation promoted by Al3Ti and TiB2 particles exist in the melt during solidification. When $>0.3 \mathrm{wt} \%$ yttrium is added, the tensile strength drops. This could be due to the intermediate compound containing yttrium aggregates and grows, cuts 
up the $\alpha$-Al matrix and weakens the obstruction to the boundary movement [14].

\subsection{Elongation}

Ductility of a metal can be measured by its elongation or strain at specific point in the stress-strain curve. In this study, strain at fracture is taken into consideration to analyze the effect of yttrium on the ductility of A356. The original unrefined A356 has a tensile strain of 0.064 . When it is added with $\mathrm{TiB}$ grain refiner to contain 0.1 wt $\% \mathrm{Ti}$ and $0.02 \mathrm{wt} \% \mathrm{~B}$, the ductility does not improve significantly; its tensile strain is 0.069 . When yttrium is added from 0.1 to $0.5 \mathrm{wt} \%$, the tensile strain improves slowly to the maximum value of 0.076 at $0.3 \mathrm{wt} \% \mathrm{yt}-$ trium. Similarly to harness and tensile strength, further addition of yttrium exceeding $0.3 \mathrm{wt} \%$ does not improve ductility continuously. The strain behavior of yttriummodified A356 is shown in Figure 5.

\subsection{Microstructural Analysis}

The microstructures of the A356 and its Y-Ti-B-grain refined specimens are shown in Figures 6(a)-(g) (all scale lengths are $0.133 \mathrm{~mm}$ ). The original A356 gravity die casting has coarse $\alpha$-Al dendritic microstructure with very fine and rod-like eutectic phase. The addition of 0.1 wt\% Ti and $0.02 \mathrm{wt} \% \mathrm{~B}$ into the melt is observed to have refined the dendritic structure. It is still a dendritic structure but characterized with smaller secondary dendrite arm spacing. The addition of yttrium from 0.1 to $0.5 \mathrm{wt} \%$ into the melt is seen to have refined the microstructure potently. Yttrium is found to be able to reduce the secondary dendrite arm spacing from the unrefined A356 coarse SDAS of $0.037 \mathrm{~mm}$ to the finest SDAS of 0.01 $\mathrm{mm}$ in $0.3,0.4$ and $0.5 \mathrm{wt} \%$ yttrium-refined casting. Smaller SDAS is known to strengthen the casting and produce better mechanical properties of tensile strength and elongation. Increasing amount of yttrium is observed to decrease the eutectic silicon phase and the grain boundary becomes narrow and continuous. In this invest-

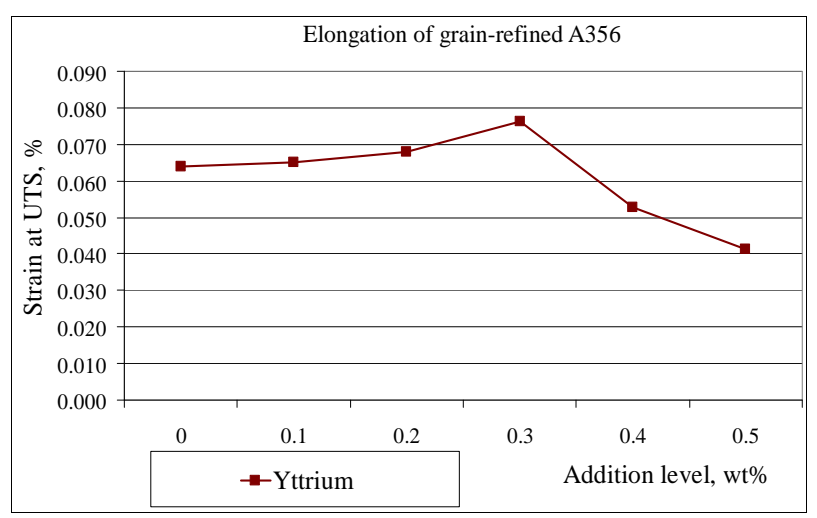

Figure 5. Elongation at fracture. tigation, yttrium is found unable to transform the $\alpha$-Al phase from dendritic structure into globular structure. Previous study showed that such a globular transformation in A356 can only be achieved by T6 heat treatment [15]. Yttrium is found to be able to modify the silicon eutectic phase into a more fibrous form as compared with that of unrefined A356. Adding yttrium into A356 will produce the high-melting point Al-Y compounds at the solid/liquid interface and lead to the formation of solute undercooling layer, suppression of the growth of $\alpha$-Al grains and subsequently grain refine the dendritic structure of $\alpha$-Al matrix [16].

\subsection{XRD and XRF Analysis}

A typical XRD diffractogram for $0.3 \mathrm{wt} \%$ yttrium inoculated A356 is shown in Figure 7. The search function of the XRD software does not detect any significant yttrium-aluminum based compounds. Based on the searched results for all samples, the following compounds were found: $\mathrm{Al}_{9} \mathrm{Si}, \mathrm{Al}_{0.86} \mathrm{Zn}_{0.14}, \mathrm{Al}_{0.95} \mathrm{Mg}_{0.05}, \mathrm{Al}_{0.86} \mathrm{Zn}_{0.14}$ and $\mathrm{Ti}$. It is the limitation of the XRD machine used for not being able to detect the low contents of yttrium and its associated compound. However, when comparing with the XRD diffractogram of other researchers [15], the spectrum looks similar and it is expected to contain the phases of $\alpha$-Al, $\mathrm{TiAl}_{3}, \mathrm{AlY}_{3}, \mathrm{AlY}_{2}, \mathrm{TiC}$ and $\mathrm{TiB}_{2}$. It has been reported that the intermediate compound of AlY that aggregates along grain boundaries and hence enhances grain boundaries to resist slipping or dislocation [16]. This in turn will improve the tensile strength of the casting.

The XRF analysis for A356 and its Ti-B and Y inoculated alloys is shown in Table 2. The main elements to be highlighted are Al, Si, Ti, B and Y. The mechanical testing results show that the optimal inoculation level to improve Ti-B grain refinement efficiency is when the atm\% ratio of $\mathrm{Y} / \mathrm{B}$ is 14.5 and 2.9 for $\mathrm{Y} / \mathrm{Ti}$.

\section{Conclusions}

The combined effect of grain refiners Al-5Ti-1B (fixed at $0.1 \mathrm{wt} \% \mathrm{Ti}$ and $0.02 \mathrm{wt} \% \mathrm{~B}$ ) and yttrium on the mechanical properties of A356 gravity die castings has been studied. Based on the mechanical testing and metallographic examination conducted for the specimens, the following conclusions can be drawn:

1) $0.3 \mathrm{wt} \%$ yttrium renders the highest hardness value of 23.88 HRA (60 kgf), a 20\% improvement compared to A356

2) Grain refinement with $0.3 \mathrm{wt} \%$ addition of yttrium shows the greatest improvement in tensile strength by $40 \%$. This shows that yttrium can significantly improve tensile strength of A356.

3) $0.3 \mathrm{wt} \%$ yttrium also yields the best ductility. How- 


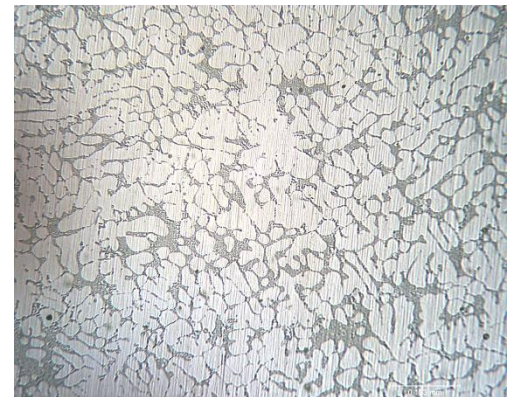

(a)

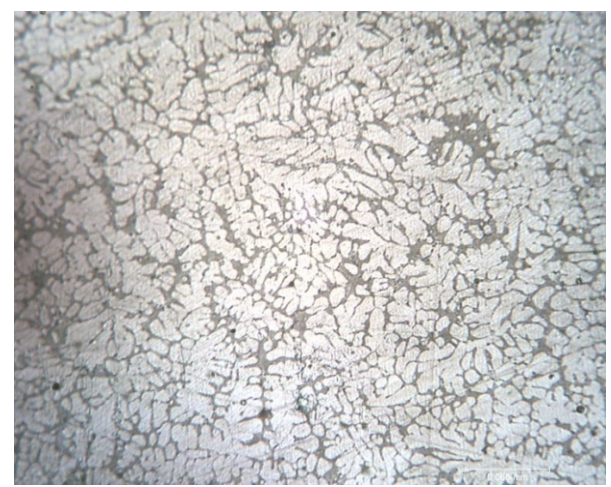

(d)

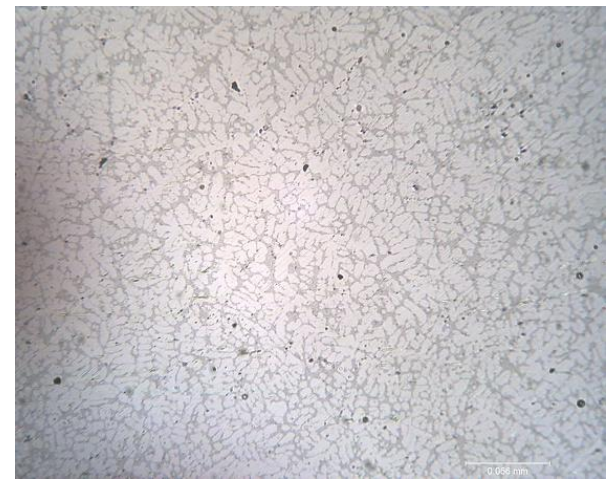

(f)

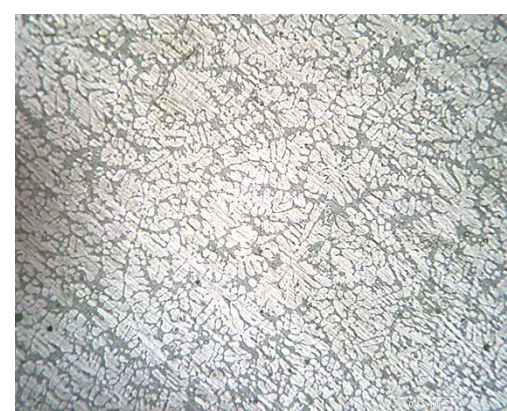

(b)

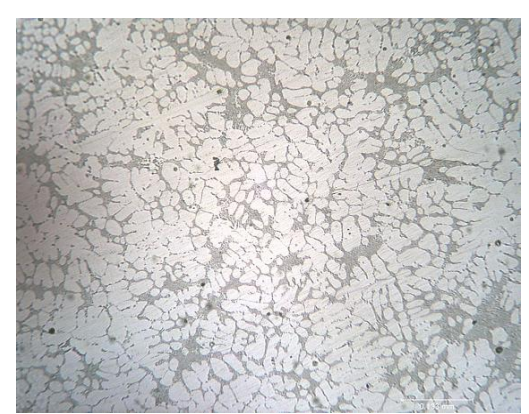

(c)

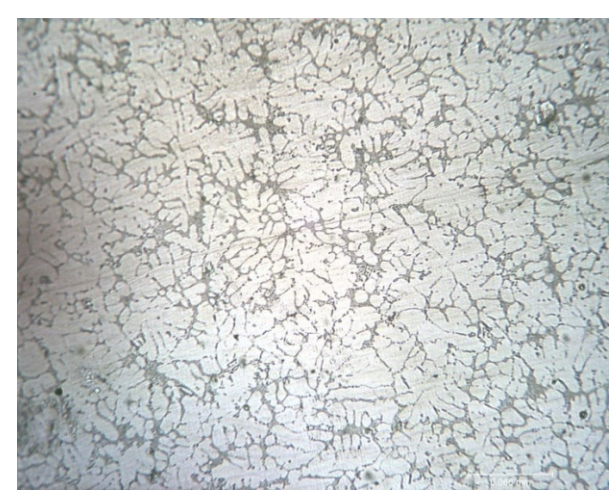

(e)

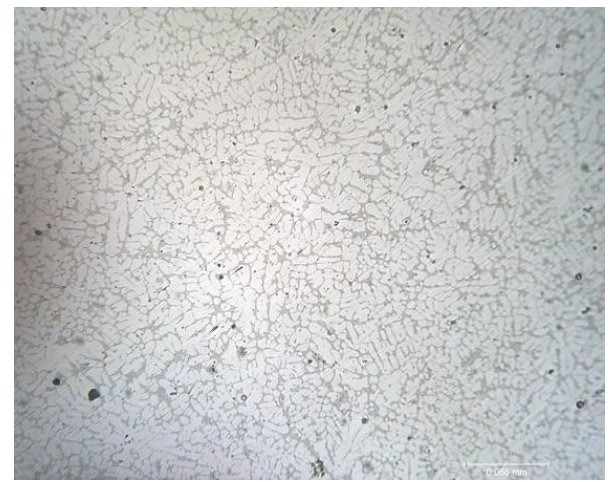

(g)

Figure 6. (a)-(g): Microstructures of test specimens; (a) A356; (b) 0.1 wt \% Ti + 0.02 wt\% B; (c) 0.1 wt\% Y; (d) 0.2 wt \% Y; (e) 0.3 wt \% Y; (f) 0.4 wt \% Y; (g) 0.5 wt \% Y.

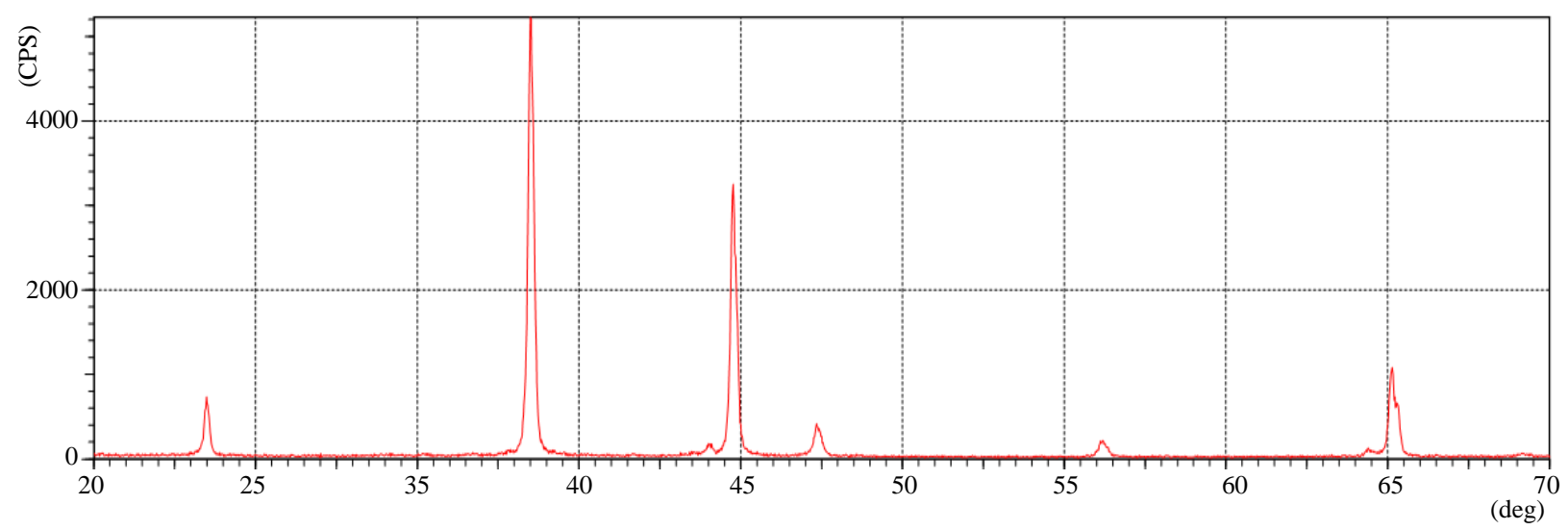

Figure 7. XRD diffractogram of $0.3 \mathrm{wt} \% \mathrm{Y}$. 
Table 2. XRF analysis of chemical compositions.

\begin{tabular}{|c|c|c|c|c|c|c|c|}
\hline \multirow[t]{2}{*}{ Element } & \multicolumn{7}{|c|}{ Sample } \\
\hline & A356 & Ti-B & 0.1 wt $\%$ Y & 0.2 wt $\%$ Y & 0.3 wt $\%$ Y & $0.4 \mathrm{wt} \% \mathrm{Y}$ & 0.5 wt $\%$ Y \\
\hline $\mathrm{Al}, \mathrm{atm} \%$ & 88.53 & 89.21 & 88.03 & 89.78 & 88.18 & 89.67 & 89.47 \\
\hline Si, atm\% & 10.78 & 10.82 & 11.19 & 10.33 & 10.93 & 10.62 & 10.48 \\
\hline Ti, atm\% & 0.06 & 0.10 & 0.09 & 0.09 & 0.10 & 0.10 & 0.11 \\
\hline $\mathrm{Y}, \mathrm{atm} \%$ & 0.04 & 0.04 & $0.11-$ & 0.21 & 0.29 & 0.38 & 0.51 \\
\hline B, atm\% & 0.02 & 0.02 & 0.02 & 0.02 & 0.02 & 0.02 & 0.02 \\
\hline $\mathrm{Y} / \mathrm{B}$ ratio & 2 & 2 & 5.5 & 10.5 & 14.5 & 19 & 25.5 \\
\hline Y/Ti ratio & 0.67 & 0.4 & 1.22 & 2.33 & 2.9 & 3.8 & 4.64 \\
\hline
\end{tabular}

ever the improvement is not significant, it improves only by $0.012 \mathrm{~mm} / \mathrm{mm}$.

4) Microstructural analysis shows that yttrium is able to refine grain size by reducing the SDAS and produces more fibrous eutectic silicon phase. However, the dendritic structure of $\alpha-\mathrm{Al}$ is still unchanged.

5) Addition level of $>0.3 \mathrm{wt} \%$ yttrium will not further improve the mechanical properties of A356.

\section{Acknowledgements}

The author would like to thank UTAR for providing research facilities and financial support for this research.

\section{REFERENCES}

[1] A. K. Prasada Rao, K. Das, B. S. Murty and M. ChakraBorty, "Microstructural Features of As-Cast A356 Alloy Inoculated with Sr, Sb Modifiers and Al-Ti-C Grain Refiner Simultaneously,” Materials Letters, Vol. 62, No. 2, 2008, pp. 273-275. doi:10.1016/j.matlet.2007.05.020

[2] H. L. Zhao, H. L. Baia, W. G. Jun and S. K. Guana, "Preparation of Al-Ti-C-Sr Master Alloys and Their Refining Efficiency on A356 Alloy,” Materials Characterization, Vol. 60, No. 5, 2009, pp. 377-383. doi:10.1016/j.matchar.2008.10.012

[3] R. Prasada, A. K. Das, K. Murty and B. S. Chakraborty, "On the Modificationand Segregation Behavior of Sb in Al-7Si Alloy during Solidification,” Materials Letters, Vol. 62, No. 12-13, 2007, pp. 2013-2016.

[4] B. Chalmers, "The Structure of Ingots," Journal of the Australian Institute of Metals, Vol. 8, 1963, pp. 255-263.

[5] S. A. Metz and M. C. Flemings, “A Fundamental Study of Hot Tearing,” The Merton C. Flemings Symposium on Solidification and Materials Processing, USA Publishers, Cambridge, 2000, pp. 181-188.

[6] D. Apelian, G. K. Sigworth and K. R. Whaler, “Assessment of Grain Refinement and Modification of Al-Si Foundry Alloys by Thermal Analysis,” AFS Transactions,
Vol. 92, 1984, pp. 297-307.

[7] D. G. McCartney, “Grain Refining of Aluminium and Its Alloys Using Inoculants,” International Materials Reviews, Vol. 34, 1989, pp. 247-260.

[8] J. A. Spittle, J. M. Keeble and M. A. Meshhedani, "The Grain Refinement of Al-Si Foundry Alloys,” Light Metals, 1997, pp. 795-800.

[9] W. S. Miller, L. Zhuang, J. Bottema, et al., "Recent Development in Aluminum Alloys for the Automotive Industry," Materials Science and Engineering, Vol. 280, No. 1, 2000, pp. 37-49. doi:10.1016/S0921-5093(99)00653-X

[10] Y. Birol, "Grain Refining Efficiency of Al-Ti-C Alloys,” Journal of Alloys and Compounds, Vol. 422, No. 1-2, 2006, pp. 128-131. doi:10.1016/j.jallcom.2005.11.059

[11] W. O. Ngalaa and H. J. Maier, “Creep-Fatigue Interaction of the ODS Superalloy: PM 1000,” Materials Science and Engineering A, Vol. 510-511, 2009, pp. 429-433. doi:10.1016/j.msea.2008.06.056

[12] P. J. Zhou, J. J. Yu and X. F. Sun, "Role of Yttrium in the Microstructure and Mechanical Properties of a BoronModified Nickel-Based Superalloy,” Scripta Materialia, Vol. 57, No. 7, 2007, pp. 643-646. doi:10.1016/j.scriptamat.2007.06.003

[13] H. Z. Li, X. P. Liang and F. F. Li, "Effect of Y Content on Microstructure and Mechanical Properties of 2519 Aluminum Alloy," Transaction of Nonferrous Metals Society of China, Vol. 17, No. 6, 2007, pp. 1194-1198. doi:10.1016/S1003-6326(07)60248-9

[14] "Heat Treating, Metals Handbook," 9th Edition, ASM International, Metals Park, Vol. 4, 1981.

[15] C. X. Xu, B. F. Lu and Z. L. Lü, "Grain Refinement of AZ31 Magnesium Alloy by Al-Ti-C-Y Master Alloy," Journal of Rare Earths, Vol. 26, No. 4, 2008, pp. 604608. doi:10.1016/S1002-0721(08)60146-5

[16] Y. Y. Chen, Y. F. Si and F. T. Kong, "Effects of Yttrium on Microstructures and Properties of Ti-17Al-27Nb Alloy," Transaction of Nonferrous Metals Society of China, Vol. 16, No. 2, 2006, pp. 316-320. doi:10.1016/S1003-6326(06)60054-X 